\title{
Ultrafiltration Mixed Matrix Membranes Based on Mesoporous Silica (MCM-41, HMS)Embedded in Polysulfone
}

\begin{abstract}
ANCA RAZVAN, DANIELA F. POPA, OVIDIU OPREA, EUGENIU VASILE, FLORINA DUMITRU*, GHEORGHE NECHIFOR
Politehnica University of Bucharest,1 Polizu Str., 011061, Bucharest, Romania

Three composite membranes (M1-M3), with mesoporous silica (MCM-41 or HMS-C12/C16-type) embedded in polysulfone (Psf) were obtained by phase-inversion method and their performances were tested for use in ultrafiltration membrane processes. The structures of M (Psf 12\%, reference membrane), M1 (Psf 12\% + MCM-41), M2 (Psf 12\% + HMS-C12), M3 (Psf 12\% + HMS-C16) have been assessed by FTIR, TG-DSC and SEM-EDAX and the morphology and their hydrodynamic performances have been evaluated by contact angle measurements, dead-end and cross-flow filtration experiments.
\end{abstract}

Keywords: MCM-41, HMS mesoporous silica, polysulfone, blend membranes, ultrafiltration

Polysulfone (Psf) polymers possess excellent chemical and thermal stabilities, high solubility in polar aprotic solvents, good adaptability to the preparation of dense, microporous membranes by phase inversion process and theyare effectively used in micro-, ultrafiltration and reverse osmosis processes as well as in the development of composite membranes for transport or gas separation [15]. The hydrophobicity of polysulfone polymers often leads to severe membrane fouling and decline of permeability through membranes. One way to overcome this drawback may be achieved by improving of hydrophilicity of membranes by blending the polymeric matrix with porous or non-porou inorganic fillers [6-11]. Among numerous inorganic fillers, silica, $\mathrm{SiO}_{2}$, in form of nonporous (nano) particles or as mesoporous material, is extensively used due to its facile preparation, mild reactivity and wellknown chemical properties [8-24]. Numerous examples of hybrid membranes incorporated with solid silica particles ( $\mathrm{SiO}_{2}$ ) have been reported and demonstrated that the addition of $\mathrm{SiO}_{2}$ into polymer film is beneficial to membrane separation performance either in terms of membrane flux or selectivity [8-24]. Ahmad et al. [18] demonstrated, in a filtration experiment for oil-in-water emulsion separation, that embedding $\mathrm{SiO}_{2}$ nanoparticles in Psf membrane lead to a 16 times higher permeate flux $\left(17.32 \mathrm{~L} / \mathrm{m}^{2} \mathrm{~h}\right)$ for the modified membrane (PSf 15\% wt with $1-5 \%$ wt SiO in Ndimethylacetamide) than the unmodified membrane (PSf $15 \%$ wt in $\mathrm{N}$-dimethylacetamide, $1.08 \mathrm{~L} / \mathrm{m}^{2} \mathrm{~h}$ ). The antifouling properties were also improved with the increasing amount of $\mathrm{SiO}_{2}$ nanoparticles (from 1\% to $5 \%$ wtSiO in casting solution). A major problem of such mixed matrix membranes, membranes with solid particles incorporated, is represented by tendency of the nonporous particles to migrate to the membrane surface during the phase inversion process, which leads to a decrease in the effective filtration area of the membrane $[25,26]$.

Compared to solid silica particles, mesoporous silicas have special properties such as higher specific surface area, porosity, tunable pore structures with inner surface easy to functionalize, and the porous nature of the inorganic fillers gives them a high water permeability through mixed matrix membrane filler-polymer. Mesoporous MCM-41 materials have been incorporated in polyethersulfone (PES) [20] and the resulted membranes (with 2\% wt MCM-41) exhibited excellent hydrophilicity, water permeability and good antifouling performance, efficient in raw water purification experiments [14, 20]; in polysulfone (Psf) to enhance the gas permeability $\left(\mathrm{N}_{2^{\prime}} \mathrm{O}_{2^{\prime}} \mathrm{CH}_{4}\right.$ and $\left.\mathrm{CO}_{2}\right)$ [21].

On the base of our previous achievements $[27,28]$, mesoporous silicas of MCM-41 or HMS type were prepared via a surfactant-assembly Stöber sol-gel process and then incorporated into Psf casting solution to prepare novel composite membranes: M1 (Psf 12\% + MCM-41), M2 (Psf $12 \%+$ HMS-C12), M3 (Psf 12\% + HMS-C16) whose structures, morphologies and performances have been assessed by FTIR, TG-DSC, SEM-EDAX, contact angle measurements, and dead-end and cross-flow filtration experiments.

\section{Experimental part}

\section{Techniques and materials}

All the raw materials were commercially available and used as received. Polysulfone (BASF, ULTRASON $®$ - S-2010, white powder, $1.24 \mathrm{~g} / \mathrm{cm}^{3}$, with low viscosity in organic solvents, $50 \mathrm{~mL} / \mathrm{g}, 25^{\circ} \mathrm{C}$, and an average molecular weight of $40000 \mathrm{Da}$ ) has been used as polymer support.

FTIR spectra were recorded with a Bruker Tensor 27 spectrophotometer, with the ATR sampling unit, in the wavenumbers range of $500-4000 \mathrm{~cm}^{-1}$.

Thermal analysis TG-DSC was carried out with a Netzsch 449C STA J upiter. Samples were placed in open $\mathrm{Al}_{2} \mathrm{O}_{3}$ crucible and heated with 10 degrees. $\mathrm{min}^{-1}$ from room temperature to $900^{\circ} \mathrm{C}$, under the flow of $20 \mathrm{~mL} \cdot \mathrm{min}^{-1}$ dried air. An empty $\mathrm{Al}_{2} \mathrm{O}_{3}$ crucible was used as reference.

SEM images were recorded on a SEM/EDAX High Resolution Scanning Electron Microscope, Quanta Inspect F FEG (resolution 1.4nm) with EDAX (133 eV resolution at MnKá) - FEl Company.

Contact angle measurements were carried out with Contact Angle Meter - KSV Instruments CAM 100. Each contact angle value represents the average of a minimum of 5 measurements.

Dead-end and cross-flow filtration experiments were carried out to characterize the performance of the prepared membranes. The ultrafiltration experiments were conducted using a laboratory-scale dead-end (DE) and cross-flow (CF) filtration system (equipped with a variable speed driven centrifugal pump: $Q=40 \mathrm{~L} / \mathrm{min}, \mathrm{n}=287 \mathrm{rpm}$, and $\mathrm{H}_{\mathrm{a}}=3 \mathrm{bar}$ ) at temperature of $25^{\circ} \mathrm{C}$ and pressures of $0.5,1,2,2.5$ and 3 bar. For each type of membrane, the

* email: florina.dumitru@upb.ro 
water flux was determined by measuring the collecting time for the volume of $100 \mathrm{ml}$ of permeate. The membranes diameter was $36 \mathrm{~mm}$. The permeate volume was determined on steady flow conditions. The flux $(J)$, defined as the flow rate of water passing through the membrane, per unit area of membrane, was calculated using the formula: $J=\frac{Q_{p}}{A_{m}}\left[\mathrm{~L} / \mathrm{m}^{2} \cdot \mathrm{h}\right]$, where: $\mathrm{Q}_{\mathrm{p}}=$ filtrate flow rate through membrane $[L / h], A_{m}=$ surface area of membrane $\left[\mathrm{m}^{2}\right]$.

Synthesis of mesoporous silica: MCM-41, HMS-C12, HMS-C16

MCM-41

MCM-41 mesoporous silica has been prepared by using cetyltrimethylammonium bromide (CTAB) as structuredirecting agent and tetraethoxysilane (TEOS) as sol precursor to form silica mesopores, according to adapted literature procedures $[27,29,30]$. The reaction mixture was composed of 1.0 CTAB: 9.21 TEOS: $2.55 \mathrm{NaOH}: 4857$ $\mathrm{H}_{2} \mathrm{O}$ (molar ratios).

\section{HMS-C12, HMS-C16}

Hexagonal mesoporous silicas (HMS) have been synthesized following the literature procedures $[29,31]$ : HMS-C12 and HMS-C16 were prepared by hydrolysis of TEOS in presence of $\mathrm{C}_{\mathrm{n}} \mathrm{H}_{2 n+1} \mathrm{NH}_{2}$ primary amines $\left(\mathrm{C}_{12} \mathrm{H}_{25} \mathrm{NH}_{2}\right.$, dodecylamine and ${ }^{2} \mathrm{C}_{16} \mathrm{H}_{33} \mathrm{NH}_{2}$, hexadecylamine) as structure-directing agents ( $n=12$ for HMSC12 and $n=16$ for HMS-C16, respectively), water and ethanol. For each material, the molar ratio in the reaction mixture was: 1.0 TEOS : $0.27 \mathrm{C}_{\mathrm{n}} \mathrm{H}_{2 \mathrm{n}+1} \mathrm{NH}_{2}: 9.09 \mathrm{C}_{2} \mathrm{H}_{5} \mathrm{OH}$ : $29.6 \mathrm{H}_{2} \mathrm{O}$.

\section{Membranes preparation}

Polysulfone reference membrane M (Psf 12\%) and Psf/ mesoporous SiO membranes: M1 (Psf 12\% + MCM-41), M2 (Psf 12\% + HMS-C12), M3 (Psf 12\% + HMS-C16) were prepared bynon-solvent induced phase inversion method. Casting solutions were prepared by dissolving $1 \%$ wt mesoporous silica (MCM-41, HMS-C12 or HMS-C16) and $12 \%$ wt Psf in dimethylformamide (DMF). The blending mixtures were cast in thin films of $0.4 \mathrm{~mm}$ on a glass plate using a film casting device and then immersed in a coagulation bath of distilled water $\left(25^{\circ} \mathrm{C}\right)$ for $2 \mathrm{~h}$.

\section{Results and discussions}

Mesoporous silicas: MCM-41, HMS-C12, HMS-C16 were synthesized and completely characterized to assess their porosity, pore size, ordered structure and thermal stability as reported in our previous paper [29].

\section{FTIR spectra}

In the FTIR spectra of M, M1-M3 membranes (Fig. 1), the absorption maxima attributed to the structure of polysulfone: $1108 \mathrm{~cm}^{-1}(\mathrm{C}-0), 1150 \mathrm{~cm}^{-1}\left(\mathrm{R}\left(\mathrm{SO}_{2}\right)-\mathrm{R}\right), 1247$ $\mathrm{Cm}^{-1}$ (C-0), 1489, $1587 \mathrm{~cm}^{-1}$ ( $\mathrm{C}=\mathrm{C}$ aromatic), and 2968 $\mathrm{cm}^{-1}(\mathrm{CH}$ aromatic), respectively, are present. The stretching vibration of Si-O-Si bond appear at $\sim 1100 \mathrm{~cm}^{-1}$ but it is obscured by polysulfone vibration bands, the major compound in the composite membranes.

\section{Thermal analysis (TG-DSC)}

The thermal analysis curves (TG-DSC) for M, M1-M3 membranes are depicted in figure $2(\mathrm{a})$ and $(\mathrm{b})$ and one can observe that the TG-DSC curves are very similar in shape for all four membranes. The total experimental mass

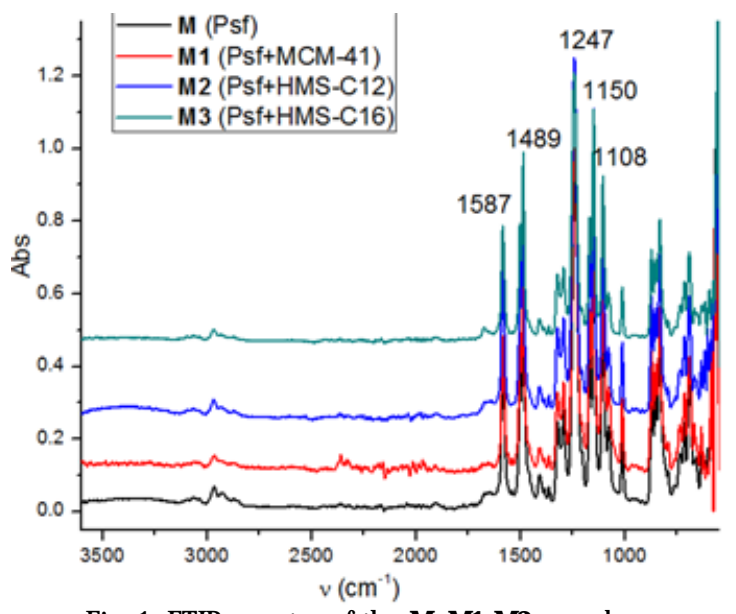

Fig. 1. FTIR spectra of the M, M1-M3 membranes
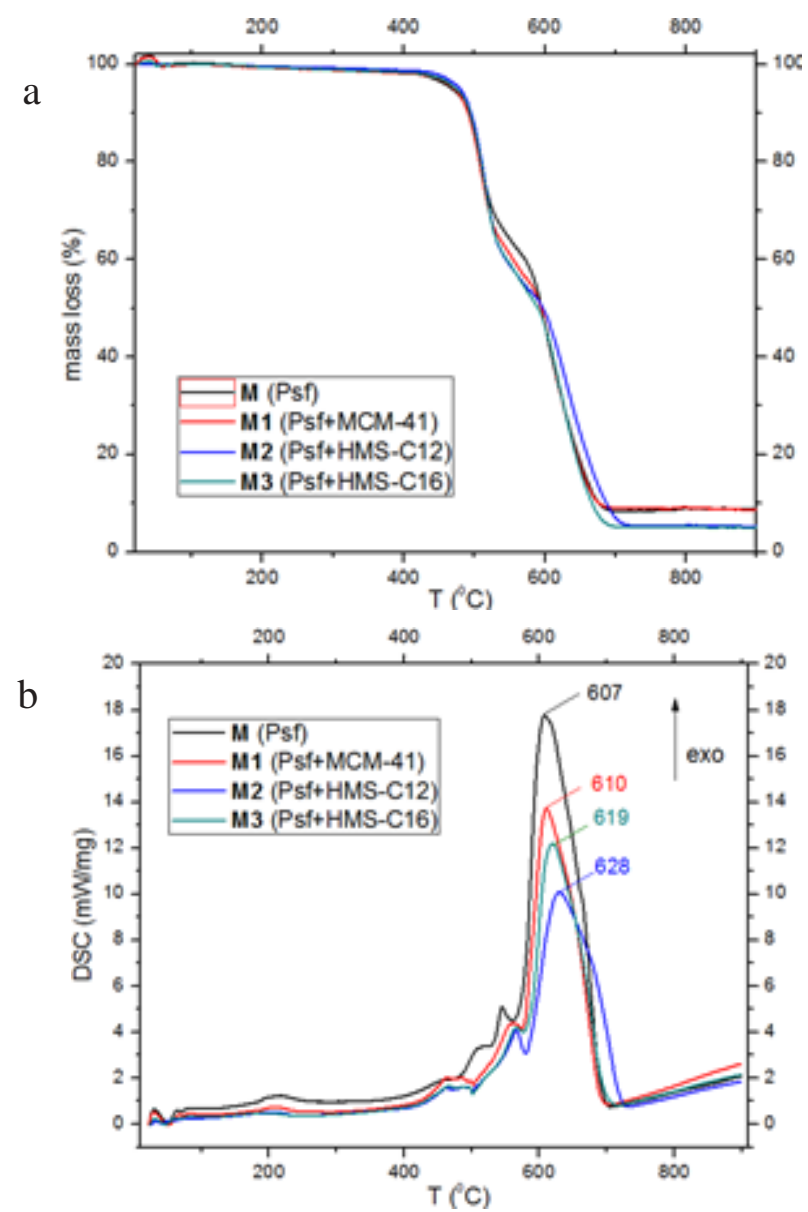

Fig. 2. TG curves (a) and DSC curves (b) for membranes M, M1-M3

loss is $91.02 \%$ wt for $\mathbf{M}, 91.25 \%$ wt for $\mathbf{M 1}, 94.70 \%$ wt for M2, and $94.92 \%$ wt for $\mathbf{M 3}$, respectively.

Thermal decomposition of $\mathbf{M}, \mathbf{M} 1-\mathbf{M} 3$ membranes is characterised by three decomposition stages, in the temperature ranges: (I) $420-520^{\circ} \mathrm{C}$, (II) $520-590^{\circ} \mathrm{C}$, (III) $590-700^{\circ} \mathrm{C}$, characterized by the mass losses (I) 27.49 $36.75 \%$ wt, (II) $12.73-16.77 \%$ wt, and (III) $42.67-47.38 \%$ wt, respectively. DSC curves for M, M1-M3 membranes (Fig. 2 b) showed two moderate exothermic effects, $420^{\circ} \mathrm{C}$ $<\mathrm{T}<565^{\circ} \mathrm{C}$, assigned to the beginning of the decomposition process of polysulfone polymer. The strong exothermic effect centered at $607^{\circ} \mathrm{C}$ for $\mathrm{M}$ (Psf $12 \%$ ), at $610^{\circ} \mathrm{C}$ for M1 (Psf $12 \%+\mathrm{MCM}-41$ ), at $619^{\circ} \mathrm{C}$ for M2 (Psf $12 \%+$ HMS-C12), and at $628^{\circ} \mathrm{C}$ for M3 (Psf $12 \%+$ HMS-C16), respectively, is attributed to the combustion of polysulfone backbone. Moreover, for M, M1-M3 membranes, the decomposition temperatures $\left(T_{d}\right)$ and the glass transition 
temperatures $(T)$ have been determined. The literature data showed that $T_{\text {and }} T_{d}$ for Psf membranes are $189^{\circ} \mathrm{C}$ and $471.95^{\circ} \mathrm{C}$ [32], and $w e$ found for $\mathbf{M}$ (Psf $12 \%$ ) $\mathrm{T}=$ $189.3^{\circ} \mathrm{C}$ and $\mathrm{T}_{\alpha}=484.1^{\circ} \mathrm{C}$, values that are very close to those reported in literature. Generally, these temperatures increase for membranes with inorganic nanoparticles incorporated, and we determined values slightly higher (in particular for decomposition temperatures, $T_{1}$ ) for M1 (Psf $12 \%+$ MCM-41) $: \mathrm{T}=192.7^{\circ} \mathrm{C}$ and $\mathrm{T}=485.0^{\circ} \mathrm{C}$, for M2 (Psf 12\%+HMS-C12): $\uparrow^{\circ}=187.2^{\circ} \mathrm{C}$ and $\mathrm{T}=489.7^{\circ} \mathrm{C}$, and for M3 (Psf 12\%+HMS-C16): $\mathrm{T}^{\circ}=187.0^{\circ} \mathrm{C}$ and $\mathrm{T}_{d}=488.1^{\circ} \mathrm{C}$. The increasing of decomposition temperatures $\left(T_{d}\right)$ is attributed to the blending of mesoporous silicas with polysulfone solutions and to the subsequent intermolecular interactions established between $\mathrm{SiO}_{2}$ and polymeric chains that lead to an enhanced rigidity of polymeric films and, hence, to enhanced thermal stability of mixed matrix membranes.

\section{Scanning electron microscopy SEM/EDAX}

Membranes cross-section structures were visualized by using scanning electron microscopy (SEM). As presented in figure 3, the reference membrane $\mathbf{M}$ (Psf 12\%) has large pores and a thickness of 50-60 $\mu \mathrm{m}$. For M1 (Psf $12 \%+$ MCM41), M2 (Psf 12\%+HMS-C12), M3 (Psf 12\%+HMS-C16) (Fig.

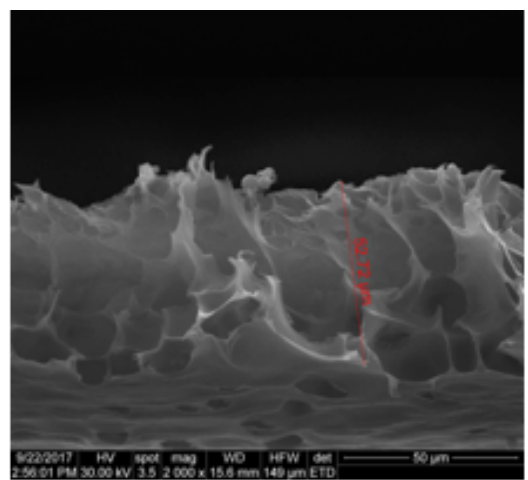

Fig. 3. SEM micrograph of transversal section through M (Psf 12\%)

membrane

4 a) the SEM images revealed that the thin film composite membranes have very similar morphologies with asymmetric structures which comprise an active film with mesoporous $\mathrm{SiO}_{2}$ incorporated.

Energy dispersive X-ray spectroscopy (Fig. 4 b), used in conjunction with SEM, confirmed that the mesoporous silicas: MCM-41, HMS-C12, HMS-C16 were incorporated into the Psf membranes as indicated by the spectral lines of Si (from SiO ) at $1.75 \mathrm{keV}$ for M1 (Psf 12\%+MCM-41), at $1.74 \mathrm{keV}$ for M2 (Psf $12 \%+$ HMS-C12), and at $1.75 \mathrm{keV}$ for M3 (Psf 12\%+HMS-C16), respectively.
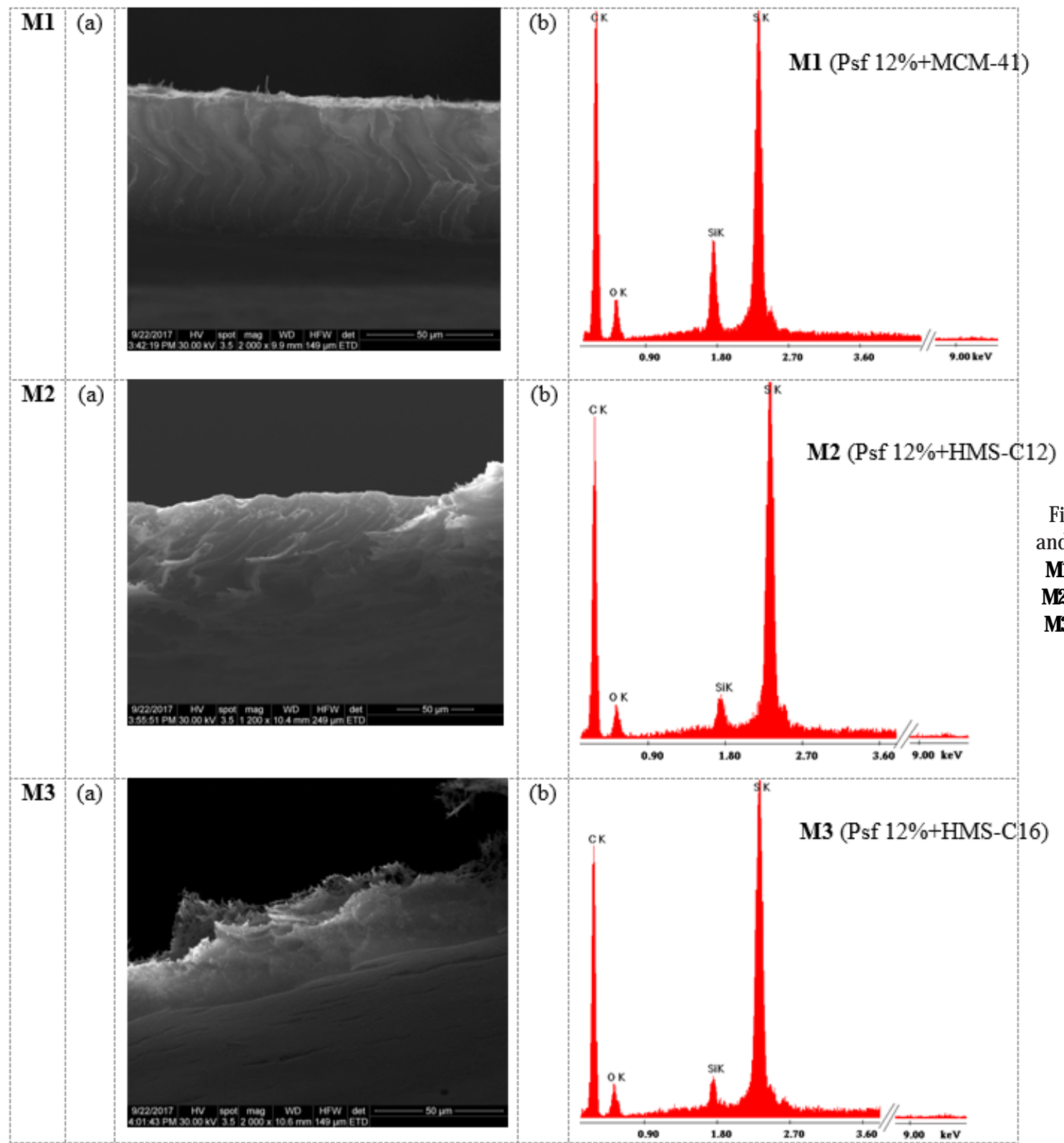

Fig. 4. SEM images (a) and EDAX patterns $(b)$ of M1 (Psf 12\%+MCM-41), M2 (Psf 12\%+HMS-C12), M3 (Psf 12\%+HMS-C16) membranes 
Table 1

WATER FLUX VALUES FOR M, M1-M3 MEMBRANES IN DEAD-END AND CROSS-FLOW EXPERIMENTS

\begin{tabular}{|c|c|c|c|c|c|c|c|c|}
\hline \multirow{3}{*}{$\begin{array}{l}\text { Pressure } \\
\text { (bar) }\end{array}$} & \multicolumn{8}{|c|}{$J\left(L / m^{2} \cdot h\right)$} \\
\hline & \multicolumn{2}{|c|}{$\begin{array}{c}M \\
\left(\mathrm{Psf}_{\mathrm{s}} 12 \%\right)\end{array}$} & \multicolumn{2}{|c|}{ 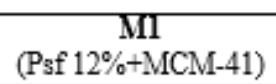 } & \multicolumn{2}{|c|}{$\begin{array}{c}\text { M2 } \\
\text { (Psf } 12 \%+H M S-C 12)\end{array}$} & \multicolumn{2}{|c|}{$\begin{array}{c}\text { M3 } \\
\text { (Psf } 12 \%+\text { HMS-C16) }\end{array}$} \\
\hline & $\mathrm{DE}$ & $\mathrm{CF}$ & $\mathrm{DE}$ & $\mathrm{CF}$ & $\mathrm{DE}$ & $\mathrm{CF}$ & $\mathrm{DE}$ & $\mathrm{CF}$ \\
\hline 0.5 & 781.6 & 123.8 & 785.9 & 210.5 & 1178.9 & 267.9 & 569.9 & 246.4 \\
\hline 1.0 & 728.6 & 265.3 & 693.5 & 310.2 & 906.8 & 357.2 & 485.2 & 258.4 \\
\hline 2.0 & 1046.9 & 717.9 & 561.4 & 471.6 & 785.9 & 491.2 & 459.3 & 320.3 \\
\hline 2.5 & 930.2 & 572.9 & 535.9 & 519.2 & 736.8 & 535.9 & 525.3 & 359.3 \\
\hline 3.0 & 905.4 & 550.0 & 561.4 & 561.4 & 693.5 & 575.1 & 537.4 & 355.1 \\
\hline
\end{tabular}

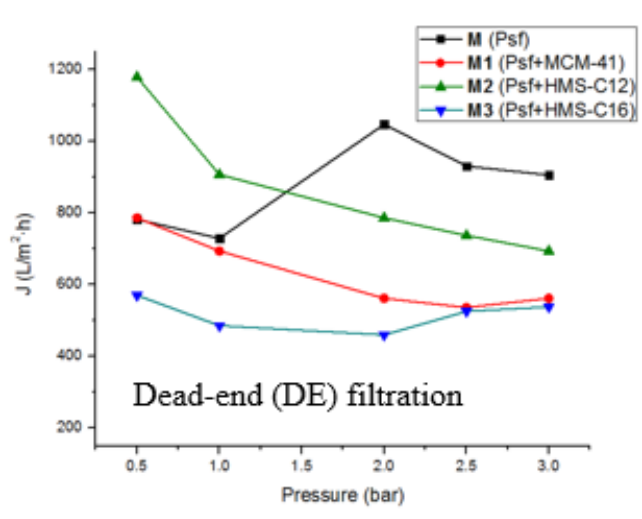

\section{Contact angle measurements}

Contact angle measurements showed that the polysulfone-mesoporous silica membranes are more hydrophilic than the reference membrane, prepared only from polysulfone. The contact angle of the reference membrane $\mathbf{M}$ (Psf $12 \%$ ) is $83.4 \pm 1.6^{\circ}$ [28] and, when mesoporous silicas (MCM-41, HMS-C12, HMS-C16) have been added to the casting mixture, the contact angle significantly decreased to $50.98 \pm 4.5^{\circ}$ for M1 (Psf $12 \%+$ MCM- 41 ), to $52.77 \pm 5.5^{\circ}$ for M2 (Psf 12\%+HMS-C12), and to $69.12 \pm 2.8^{\circ}$ for M3 (Psf $12 \%+$ HMS-C16).

\section{Dead-end and cross-flow experiments}

The influence of mesoporous silicas addition into composite membranes upon pure water permeability has been evaluated in ultrafiltration (UF) experiments: deadend (DE) and cross-flow (CF) filtration modes. Water permeability measurements showed a decrease of the of the pure water flux through M1 (Psf 12\%+MCM-41), M2 (Psf 12\%+HMS-C12), M3 (Psf12\%+HMS-C16) membranes, both in dead-end and cross-flow filtration modes, in comparison to the M (Psf 12\%) membrane used as reference (table 1, fig. 5). The decrease of the flow rate is attributed to the silica particles barrier effect against to water transport, even though the hydrophilicities of M1 (Psf $12 \%+$ MCM-41), M2 (Psf 12\%+HMS-C12), M3 (Psf $12 \%+$ HMS-C16) membranes are higher than that of $\mathbf{M}$ ( Psf $12 \%$ ) as evidenced by contact angle measurements.

The relative large water flux measured in filtration experiments and the improved hydrophilicities for M2-M3 membranes make these membranes appropriate for ultrafiltration processes.

\section{Conclusions}

In this work, mesoporous silica-Psf composite membranes: M (Psf 12\%), M1 (Psf 12\%+MCM-41), M2 (Psf 12\%+HMS-C12), M3 (Psf 12\%+HMS-C16) have been prepared by phase-inversion method. Incorporating mesoporous MCM-41, HMS-C12/C16 materials in polysulfone (Psf) lead to mixed matrix membranes with higher thermal stability as pointed out by TG-DSC analyses and with enhanced hydrophilic character assessed by contact angle measurements.

The hydrodynamic performances of the mixed matrix membranes, M1-M3 have been investigated by dead-end and cross-filtration experiments and the water permeabilities have been evaluated. The improved hydrophilicities of the M1-M3 membranes are effective for enhancing the fouling resistance and are suitable for use in ultrafiltration process, the water flux values are 123.8$717.9 \mathrm{~L} / \mathrm{m}^{2} \cdot h$ for M, 210.5-561.4 L/m².h for M1, 267.9-575.1 for M2, and $246.4-359.3 \mathrm{~L} / \mathrm{m}^{2} \cdot h$ for M3 in cross-flow filtration experiments for pressures betw een 0.5-3 bars.

\section{References}

1.NUNES, S.P., PEINEMANN K.-V., (Eds.), Membrane Technology in the Chemical Industry, Wiley/NCH Verlag GmbH, Weinheim, Germany, 4, 2001, p. 12.

2.LEE A., ELAM, J. W., DARLING, S. B., Environ. Sci.: Water Res. Technol., 2, 2016, p. 17.

3.BAKER, R.W., Membrane Technology and Applications, John Wiley $\&$ Sons, Ltd, West Sussex, England, 2004.

4.ULBRICHT, M., Polymer, 47, 2006, p. 2217.

5.LALIA, B.S., KOCHKODAN, V., HASHAIKEH, R., HILAL, N., Desalination, 326, 2013, p. 77.

6.RANA, D., MATSUURA, T., Chem. Rev., 110, 2010, p. 2448.

7.KOCHKODAN, V., JOHNSON, D. J., HILAL, N., Adv. Colloid Interface Sci., 206, 2014, p. 116.

8.AMIN, M. T., ALAZBA, A. A., Membr. Water Treat., 5(2), 2014, p. 123. 9.MOHMOOD, I., LOPES, C. B., LOPES, I., AHMAD, I., DUARTE, A. C., PEREIRA, E., Environ. Sci. Pollut. Res., 20, 2013, p. 1239.

10.HOMAYOONFAL, M., MEHRNIA, M. R., MOJTAHEDI, Y. M., ISMAIL, A. F., Desalin. Water Treat., 51, 2013, p. 3295.

11.NG, L.Y., MOHAMMAD, A.W., LEO, C.P., HILAL, N., Desalination 308, 2013, p.15.

12.W., HUIQING, TANG, B., WU, P., J. Phys. Chem. C, 116, 2012, p. 2246.

13.YU, L.-Y., XUA, Z.-L., SHEN, H.-M., YANG, H., J. Membr. Sci., 337, 2009, p. 257.

14.LI, X., HUANG, J ., ZHANG, Y., LV, Y., LIU, Z., SHU, Z., Desalin. Water Treat., 57(24), 2015, p. 10980. 
15.LI, Q., PAN, S., LI, X., LIU, C., LI, J., SUN, X., SHEN, J., HAN, W., WANG, L., Colloid Surf. A Physicochem. Eng. Asp., 487, 2015, p. 180. 16.BotTino, A., CAPANNELLI, G., DASTI, V., PIAGGIO, P., Sep. Purif. Technol. 22-23, 2001, p. 269.

17.YU, S., ZUO, X., BAO, R., XU, X., WANG, J., XU, J., Polymer, 50, 2009, p. 553.

18.AHMAD, A.L., MAJID, M.A., OOI B.S., Desalination, 268(1-3), 2011, p. 266.

19.ZHANG, Y., SHAN, L., TU, Z., ZHANG, Y., Sep. Purif. Technol. 63, 2008, p. 207.

20.HUANG, J., ZHANG, K., WANG, K., XIE, Z., LADEWIG, B., WANG, H., J. Membr. Sci., 423-424, 2012, p. 362.

21.REID, B. D., RUIZ-TREVINO, F. A., MUSSELMAN, I. H., BALKUS, K. J., FERRARIS, J. P., Chem. Mater., 13, 2001, p. 2366.

22.KIM, S., MARAND, E., IDA, J., GULIANTS, V. V., Chem. Mater., 18, 2006, p. 1149.

23.KIM, S., MARAND, E., Microporous Mesoporous Mat. 114, 2008, p. 129.

24.WANG, H., LU, X., LU, D., WANG, P., MA, J., J. Appl. Polym. Sci. 136(18), 2019, p. 47353.
25.BONADIES, I., Chapter 8 - Nanoscale Materials in Water Purification, pp. 231-246, in Nanoscale Materials in Water Purification. A volume in Micro and Nano Technologies, 2019, ed. by THOMAS, S., PASQUINI, D., LEU, S.-Y., GOPAKUMAR, D. A., Elsevier Inc.

26.ARTHANAREESWARAN, G., DEVI, T.K.S., RAAJ ENTHIREN, M., Sep. Purif. Tech., 64, 2008, p. 38.

27.ENACHE, D.F., VASILE, E., SIMONESCU, C. M., CULITA, D., VASILE, E., OPREA, O., PANDELE, A. M., RAZVAN, A., DUMITRU, F., NECHIFOR, G., RSC Adv., 8, 2018, p. 176.

28.ENACHE, D. F., POPA, G. A., VASILE, E., RAZVAN, A., OPREA, O., VOICILA, E., DUMITRU, F., Rev.Chim.(BUcharest), 68, no .11, 2017, p. 2635.

29.MEYNEN, V., COOL, P., VANSANT, E.F., Microporous Mesoporous Mater. 125, 2009, p. 170.

30.LIN, V. S.-Y., LAl, C.-Y., JEFTINIJA, S., JEFTINIJA, D. M., US2009/ 0252811, 2009.

31.P. T. TANEV, T. J. PINNAVAIA, Chem. Mater. 8, 1996, pp 2068-2079. 32.Y. YANG, P. WANG, Q. ZHENG, J. Polym. Sci. B: Polym. Phys., 44, 2006, pp. 879-887.

$\overline{\text { Manuscript received: } 11.01 .2019}$ 